\title{
Postprocedural interpretation of endoscopic retrograde cholangiopancreatography by radiology
}

\author{
Nitin Khanna MD FRCPC ${ }^{1}$, Gary May MD FRCPC FASGE ${ }^{2}$, Sydney Bass MD FRCPC ${ }^{3}$, \\ Marty Cole MD FRCPC ${ }^{3}$, Joseph Romagnuolo MD FRCPC MScEpid FASGE ${ }^{4}$
}

N Khanna, G May, S Bass, M Cole, J Romagnuolo. Postprocedural interpretation of endoscopic retrograde cholangiopancreatography by radiology. Can J Gastroenterol 2008;22(1):55-60.

BACKGROUND: With the increase in the use of endoscopic retrograde cholangiopancreatography (ERCP) (necessitating real-time interpretation), it is unknown whether post-ERCP radiologist reporting is still necessary or helpful.

OBJECTIVES: To determine the rate of discrepancy of results, and the rate of clinically relevant misses and additions, by the radiology report in a blinded setting.

METHODS: A retrospective analysis of the procedure and blinded postprocedure radiology reports of 100 consecutive ERCP cases was performed. A list of clinically relevant pathology and subgroups was made a priori. Discrepancies are described as proportions, with 95\% CIs. The radiology yield regarding pathology that was clearly demonstrated at ERCP (bile leaks and stones removed) was calculated. Clinical follow-up was used to clarify additional abnormalities reported by radiology.

RESULTS: Clinically relevant discrepancies in report pairs occurred in $29.0 \%$ of cases (95\% CI $20 \%$ to $39 \%$ ), or $40.0 \%$ if discrepancies regarding bile duct dilation are considered (95\% CI 30\% to 50\%). In 15 of 30 cases $(50.0 \%$ [95\% CI $31 \%$ to $69 \%$ ]) in which bile duct stones were removed, the radiologist did not report a stone. The radiologist did not report five of eight bile leaks (62.5\% [95\% CI 24\% to 91\%]). In seven cases (7.0\% [95\% CI 2.9\% to $13.9 \%]$ ), an additional abnormality was noted by radiology, including a biliary stricture, bile duct and pancreatic duct stones, as well as sclerosing cholangitis. However, during a mean follow-up period of 5.6 months, it appeared that these radiology interpretations were likely incorrect. Discrepancy rates did not vary among the ERCP attendings or by radiology volume.

CONCLUSIONS: Discrepancies between endoscopists' and radiologists' ERCP reports are common. Blinded radiology interpretation frequently misses important pathology, and falsely positive additional diagnoses may be made.

Key Words: Agreement; Bile leaks; CBD stone; Diagnostic test interpretation; ERCP; Radiologist

W hen endoscopic retrograde cholangiopancreatography (ERCP) was being developed, it was largely diagnostic. As such, interpretation was often assisted by an on-site radiologist, but this has ceased being a common practice in most institutions. In recent years, with the development of noninvasive

\section{Faut-il faire interpréter les cholangiopancréatogrammes endoscopiques rétrogrades par les radiologistes}

HISTORIQUE : Compte tenu de l'usage croissant de la cholangiopancréatographie endoscopique rétrograde (CPER) (nécessitant une interprétation en temps réel), on ignore s'il est encore nécessaire et utile de recourir aux rapports radiologiques post-CPER.

OBJECTIF : Déterminer les taux d'écart entre les résultats et les taux de diagnostics cliniquement pertinents omis ou ajoutés dans des rapports de radiologie à l'insu.

MÉTHODES : Les auteurs ont procédé à une analyse rétrospective des interventions et des rapports radiologiques post-intervention à l'insu touchant 100 CPER consécutives. Une liste des pathologies et des sousgroupes cliniquement pertinents a été dressée à l'avance. Les écarts sont décrits sous forme de proportions et d'intervalles de confiance à $95 \%$. Le rendement radiologique a été calculé en ce qui a trait aux pathologies qui étaient clairement visibles à la CPER (à l'exclusion des calculs et fuites biliaires). Le suivi clinique a servi à clarifier toute anomalie additionnelle signalée par le radiologiste.

RÉSULTATS : Dans les rapports appariés, des écarts cliniquement pertinents ont été notés dans 29,0\% (IC à $95 \%, 20 \%$ à $30 \%$ ) ou 40,0 \% des cas, si on tenait compte des écarts relatifs à la dilatation du canal biliaire (IC à $95 \%, 30 \%$ à $50 \%$ ). Dans 15 cas sur 30 (50\%) (IC à $95 \%, 31 \%$ à $69 \%$ ) où des calculs biliaires avaient été éliminés dans le canal biliaire, le radiologiste n'a pas fait état de la présence de calculs. Le radiologiste n'a pas signalé cinq des huit fuites biliaires (62,5\%) (IC à $95 \%, 24 \%$ à $91 \%$ ). Dans sept cas (7,0 \%) (IC à $95 \%, 2,9 \%$ à 13,9\%), une anomalie additionnelle a été notée par le radiologiste, dont stricture biliaire, calculs dans le canal pancréatique et le canal biliaire et cholangite sclérosante. Par contre, durant une période moyenne de suivi de 5,6 mois, il s'est avéré que ces interprétations radiologiques étaient probablement incorrectes. Les taux d'écarts n'ont pas varié selon les participations aux CPER ni selon le volume des examens radiologiques.

CONCLUSION : Les écarts dans les rapports de CPER des endoscopistes et des radiologistes sont courants. Avec l'interprétation radiologique à l'insu, on passe souvent à côté de pathologies importantes et d'autres diagnostics faussement positifs sont parfois posés.

${ }^{1}$ Department of Medicine (Division of Gastroenterology), University of Western Ontario, London; ${ }^{2}$ Department of Medicine (Division of Gastroenterology), University of Toronto, Toronto, Ontario; ${ }^{3}$ Department of Medicine (Division of Gastroenterology), Univerity of Calgary, Calgary, Alberta; ${ }^{4}$ Departments of Medicine (Division of Gastroenterology and Hepatology) and of Biometry, Bioinformatics and Epidemiology, Medical University of South Carolina, Charleston, South Carolina, USA

Correspondence: Dr Joseph Romagnuolo, Medical University of South Carolina, 96 Jonathon Lucas Street, CSB \#210, PO Box 250327,

Charleston, South Carolina 29425, USA. Telephone 843-792-9902, fax 843-792-8395, e-mail romagnuo@musc.edu

Received for publication March 8, 2007. Accepted July 16, 2007 
ERCP, endoscopists must interpret cholangiopancreatograms in real-time, and must make decisions about therapeutic interventions at the time of the procedure (4).

Fluoroscopy is generally necessary for ERCP, and is used both in real time and for capturing images representative of the findings and therapeutics performed. With improvements in the quality of fluoroscopic imaging and training, with on-site radiology technicians rather than radiologists, and with increased ERCP experience, endoscopists have become quite comfortable interpreting these fluoroscopic images. However, in many centres, radiologists routinely review, report and bill on the fluoroscopic images generated from the ERCP, sometimes even after therapy has already occurred; a report is necessary for the billing of their professional and technical components. In contrast to other medical scenarios, where post-treatment interpretation of $\mathrm{x}$-rays may occur and be helpful (eg, radiologist reinterpretation, after treatment was already initiated, of preliminarily interpreted chest $\mathrm{x}$-rays performed in the emergency department after treatment for heart failure or pneumonia), the rate of finding abnormalities at ERCP that are analogous to the missed subtle pulmonary nodule or wide mediastinum is unknown.

A recent article by Sweeney et al (9) suggested that postERCP interpretation of cholangiopancreatograms by radiologists added little improvement to patient management. In their study, radiologists were routinely provided with clinical history, pre- and post-ERCP diagnoses made by the endoscopist, endoscopic and radiographic findings, and a list of interventions performed. At the time of the present study, the radiologists at the University of Calgary's Advanced Therapeutic Endoscopy Centre were not routinely provided with clinical or procedural information, and are thus effectively 'blinded' in their reporting of fluoroscopic images.

The objectives of the present study were to determine the rate of discrepancy between the ERCP reports generated by the endoscopist during the procedure and by the radiologist in their post-ERCP interpretation of fluoroscopic images without input from the endoscopist, as well as to determine whether there is relevant clinical information added by the radiologist in this setting that would have a theoretical impact on patient care.

\section{What is current knowledge:}

- Historically, ERCP fees for endoscopists were based on the technical, not the interpretation aspects of the procedure. This continues to be the case.

- Because most ERCP is now therapeutic, real-time interpretation by ERCP endoscopists is critical, and has become standard.

- Interpretation of still images in other aspects of radiology (eg, ultrasound and small bowel followthrough) is generally accepted to be limited in comparison with real-time interpretation.

- Radiologists continue to 'interpret' postprocedure ERCP images, but the added benefit (or harm), after decisions about endoscopic therapy have already been made, is largely unknown.

\section{What is new:}

- Blinded interpretation of still images after ERCP appears to conflict with that of the real-time interpretation by the ERCP endoscopist, with inaccuracies with respect to common pathology such as stones and bile leaks.

- Discrepant reports have the potential to cause problems.

- Although real-life discrepancies are less common, because radiologists usually have access to a copy of the ERCP endoscopist's report, it is not clear whether this is worth the added cost in routine cases.

\section{METHODS}

A retrospective review was performed, based on the charts of consecutive patients who underwent ERCP with successful cannulation by either of two ERCP endoscopists (JR, GM) at a single tertiary academic therapeutic endoscopy referral centre between December 2002 and June 2003. ERCP procedural reports were routinely produced by the endoscopist and/or fellow at the completion of the procedure using Pentax's EndoPRO system (Pentax Medical Company, USA).

After completion of the procedure, radiologists reviewed and reported on the fluoroscopic images saved during the ERCP, without clinical history or a copy of the endoscopists' findings, and a radiology report was then sent to the endoscopist. Informed consent for ERCP was obtained from all of the patients. ERCPs were performed using digital fluoroscopy equipment (Philips Diagnost 76 Plus, Philips Electronics, USA), with the assistance of a radiology technician for fluoroscopy and image acquisition. X-ray images were taken by the endoscopist as a representation of the findings and interventions performed as usual during the ERCP. Digital captures of fluoroscopy ('fluoro grabs'), which are often of lower quality, were not used. In cases in which the radiologist's report, when received by the endoscopist, noted a finding not mentioned by the endoscopist, the endoscopist re-reviewed the films and the report, as part of standard care, and then decided on repeat intervention (eg, repeat ERCP) versus clinical and/or radiological follow-up.

The ERCP reports were reviewed for all findings reported by the endoscopist and radiologist. An a priori list of potentially clinically relevant discrepancies was developed by consensus, and included choledocholithiasis (defined as the actual removal of a stone), common bile duct (CBD) strictures, sclerosing cholangitis, bile duct leaks (eg, postlaparoscopic cholecystectomy) and pancreatic duct pathology. Discrepancies between the reports with respect to these findings were compared. CBD size was purposefully not included in this list because exact size is often not given, and the CBD size is often described in qualitative terms (eg, normal versus dilated) by both endoscopists and radiologists in their reports. Endoscopically confirmed stones removed and fluoroscopically documented leaks that were not reported by the radiologist were considered errors in the radiology report. In other cases, the available clinical and/or radiological follow-up, including need for repeat ERCP, was used to determine whether there were any clinical sequelae of these possible missed findings, in an attempt to differentiate false-negative endoscopy reports from false-positive radiology reports. 
TABLE 1

Indications for endoscopic retrograde cholangiopancreatography in 100 consecutive patients

\begin{tabular}{lc}
\hline Indication & Patients, $\mathbf{n}(\%)$ \\
\hline Suspected CBD stone without cholangitis & $25(25)$ \\
Abdominal pain* $^{*}$ & $6(6)$ \\
Abnormal liver enzymes $^{\dagger}$ & $8(8)$ \\
Acute cholangitis & $11(11)$ \\
Jaundice & $9(9)$ \\
Bile leak & $7(7)$ \\
Acute gallstone pancreatitis & $7(7)$ \\
Recurrent pancreatitis & $6(6)$ \\
Chronic pancreatitis & $5(5)$ \\
Stent removal or replacement & $5(5)$ \\
Suspected sclerosing cholangitis & $4(4)$ \\
Pancreatic pseudocyst & $2(2)$ \\
Pancreatic tumour & $1(1)$ \\
Ampullary adenoma resection & $1(1)$ \\
Total & $100(100)$ \\
\hline
\end{tabular}

${ }^{*}$ Five of these six patients underwent manometry; ${ }^{\top}$ Three of these eight patients had ductal dilation. CBD Common bile duct

\section{RESULTS}

One hundred consecutive patients who underwent ERCP (ie, with successful cannulation) between December 2002 and June 2003, and who had both an endoscopy and radiology ERCP report, were included in the study. Sixty ERCPs were performed by one endoscopist (JR) and 40 were performed by another endoscopist (GM). A total of 22 radiologists were involved in the interpretation of the fluoroscopic images generated during the ERCP. The radiologists read a median of four cases each (range one to nine cases). The patients had a mean age of 57.3 years, and $50 \%$ were women. Eighty-eight ERCPs (88\%) involved endoscopic therapy (excluding prophylactic temporary pancreatic duct stenting), nine of which involved manometry; there was one additional nontherapeutic manometry case (normal manometry). Indications for ERCP and therapeutic procedures performed are included in Tables 1 and 2, respectively. All patients had complete medical records with respect to the variables of interest.

Report discrepancies between endoscopists and radiologists were found in $29.0 \%$ of cases (95\% CI 20\% to 39\%). Only potentially clinically relevant discrepancies were considered, ie, choledocholithiasis, strictures (including sclerosing cholangitis), bile duct leaks and pancreatic pathology. The discrepancy rate was the same for both endoscopists: 24 of 60 cases (40\%) and 16 of 40 cases (40\%). When interpretation of CBD size normality was considered, the total rate of report discrepancy rose to $40.0 \%$ ( $95 \%$ CI $30 \%$ to $50 \%$ ). CBD stones were removed endoscopically but not reported by the radiologist in 15 of 30 cases $(50.0 \%$ [95\% CI 31\% to 69\%]). Of the eight patients with fluoroscopically demonstrated bile duct leaks, five leaks were missed in the radiology reports (62.5\% [95\% CI $24 \%$ to $91 \%])$.

In seven cases (7.0\% [95\% CI $2.9 \%$ to $13.9 \%]$ ), the radiologist reported a potentially clinically relevant finding that was not included in the endoscopy report (Table 3). Follow-up data were available for all of the patients who may have had a
TABLE 2

Endoscopic therapy or invasive diagnostics performed in 100 consecutive patients

\begin{tabular}{lc}
\hline Therapeutic procedure & Patients, $\mathbf{n}$ (\%) \\
\hline Invasive diagnostics ( $\mathrm{n}=15)$ & \\
Sphincter manometry & $10(10)$ \\
Cytology brushing or intrabiliary biopsy & $5(5)$ \\
Total & $15(15)$ \\
Endoscopic therapy ( $\mathrm{n}=89)^{*}$ & \\
Biliary sphincterotomy & $72(72)$ \\
Stent insertion or removal & \\
Plastic biliary stent insertion & $25(25)$ \\
Metal biliary stent insertion & $4(4)$ \\
Pancreatic stent insertion & $16(16)$ \\
Biliary plastic stent exchange/removal & $8(8)$ \\
Total & $53(53)$ \\
Stone therapy & \\
Bile duct stone removal without lithotripsy & $18(18)$ \\
Mechanical lithotripsy & $4(4)$ \\
Electrohydraulic lithotripsy & $1(1)$ \\
Pancreatic stone removal & $1(1)$ \\
Total & $24(24)$ \\
Other & \\
Pancreatic stricture dilation & $3(3)$ \\
Biliary stricture dilation & $1(1)$ \\
Cystogastrostomy & $2(2)$ \\
Ampullectomy & $1(1)$ \\
Total & $7(7)$ \\
\hline
\end{tabular}

*The numbers in this table correspond to the patients in whom this was the primary therapy performed, but due to overlapping therapies and diagnostics, the totals do not add up to 100 patients

finding missed by the endoscopist, with a mean post-ERCP follow-up period of 5.6 months (range one to 12 months). None of the patients had symptoms, signs or complications attributable to the potential finding reported by the radiologist. One person had a repeat ERCP with manometry and did not confirm the proposed abnormality (a bile duct stone). In a case in which the radiologist raised the possibility of an abnormal right main intrahepatic duct (Table 3, patient 6), the patient was symptom-free at one month but longer term follow-up was not available; this patient was thought to have insufficient follow-up to firmly resolve the discrepancy. The six remaining cases appeared to be false-positive radiology interpretations (follow-up for three to 12 months). Two of the radiologists involved in these cases had read less than five of the 100 cases in this cohort; however, the overall median case volume of these radiologists was not significantly different from that of the rest of the cohort.

\section{DISCUSSION}

Since its inception, ERCPs have revolutionized the management of pancreaticobiliary disorders. With increased experience, improved technology and knowledge about the appropriate use of ERCP, there have been significant changes in how the procedure is performed. Currently, in most centres, the ERCP team includes a therapeutic endoscopist, specialized nurses and a radiology technician. It would appear to be neither practical nor cost-effective to have a radiologist routinely present during all ERCP procedures to assist in 
TABLE 3

Details of follow-up for seven cases in which the radiologist noted an abnormality not seen by the endoscopic retrograde cholangiopancreatography (ERCP) endoscopist

\begin{tabular}{|c|c|c|c|c|c|c|}
\hline Case & Sex & $\begin{array}{l}\text { Age, } \\
\text { years }\end{array}$ & $\begin{array}{l}\text { Symptoms or signs } \\
\text { at ERCP }\end{array}$ & $\begin{array}{l}\text { Findings } \pm \text { therapy } \\
\text { per endoscopy report }\end{array}$ & $\begin{array}{l}\text { Findings per } \\
\text { radiology report }\end{array}$ & Follow-up post-ERCP \\
\hline 1 & Female & 59 & $\begin{array}{l}\text { - Abdominal pain } \\
\text { - Abnormal LEs } \\
\text { - Dilated CBD }\end{array}$ & $\begin{array}{l}\text { - Dilated CBD } \\
\text { - Normal PD } \\
\text { - Passed CBD stone* }\end{array}$ & $\begin{array}{l}\text { - Dilated CBD } \\
\text { - PD stone }\end{array}$ & - No symptoms at 12 months \\
\hline 2 & Male & 67 & • Abnormal LEs & $\begin{array}{l}\text { - Normal CBD and } \\
\text { intrahepatic ducts }\end{array}$ & - Sclerosing cholangitis* & - Normal LEs at 12 months \\
\hline 3 & Female & 56 & - Abdominal pain & $\begin{array}{l}\text { - Dilated CBD } \\
\text { - Normal PD }\end{array}$ & - Distal CBD stricture* & $\begin{array}{l}\text { - Abdominal pain unchanged } \\
\text { at three months }\end{array}$ \\
\hline 4 & Male & 49 & $\begin{array}{l}\cdot \text { Hodgkin's lymphoma with } \\
\text { cholestasis on liver biopsy } \\
\text { - Jaundice (bilirubin level } \\
>6 \times \text { normal) }\end{array}$ & $\begin{array}{l}\text { - Normal CBD and } \\
\text { intrahepatic ducts }\end{array}$ & - CBD stone & $\begin{array}{l}\text { - No abdominal pain } \\
\text { - Bilirubin level decreased to } \\
1.5 \times \text { normal } \\
\text { - LEs } 5 \times \text { normal at } 5 \text { months }\end{array}$ \\
\hline 5 & Female & 72 & $\begin{array}{l}\text { - Elevated isolated GGT } \\
\text { (other LEs and bilirubin level } \\
\text { normal) } \\
\text { • History of 'ampullary stenosis' } \\
\text { treated with sphincterotomy }\end{array}$ & $\begin{array}{l}\text { - Dilated CBD } \\
\text { - Sphincterotomy extended }\end{array}$ & - $\mathrm{CBD}$ stricture & $\begin{array}{l}\text { - GGT unchanged at three months } \\
\text { - Other LEs and bilirubin level } \\
\text { still normal }\end{array}$ \\
\hline 6 & Female & 45 & $\begin{array}{l}\text { - Abdominal pain } \\
\text { - Suspected SOD }\end{array}$ & $\begin{array}{l}\text { - Normal CBD } \\
\text { - Normal PD } \\
\text { - Normal SOM }\end{array}$ & $\begin{array}{l}\cdot \text { Normal CBD } \\
\cdot \text { Normal PD } \\
\text { - Abnormal right main } \\
\text { hepatic duct* }\end{array}$ & - No symptoms at one month \\
\hline 7 & Female & 25 & - Recurrent pancreatitis & $\begin{array}{l}\cdot \text { Normal CBD } \\
\cdot \text { Normal PD } \\
\text { - Abnormal biliary SOM } \\
\text { - Biliary sphincterotomy } \\
\text { performed }\end{array}$ & · CBD stone & $\begin{array}{l}\text { - Acute pancreatitis at } \\
\text { two months with normal LEs } \\
\text { - Repeat ERCP at three months } \\
\text { determined normal CBD with } \\
\text { abnormal pancreatic SOM, } \\
\text { and LE still normal }\end{array}$ \\
\hline
\end{tabular}

*Inconsistent finding between endoscopy reports and radiology report. CBD Common bile duct; PD Main pancreatic duct; GGT Gamma-glutamyl transpeptidase, LEs Liver enzymes; SOD Sphincter of Oddi dysfunction; SOM Sphincter of Oddi manometry

interpreting the cholangiopancreatograms while the procedure is being performed.

With improved experience and training, endoscopists have become comfortable interpreting the majority of ERCP films, whether from an outside ERCP endoscopist in a consultative setting or in real time at ERCP. Because most ERCPs at major centres are therapeutic, thoughtful interpretation of the cholangiopancreatograms must occur at the time of the procedure so that the appropriate therapy can be applied and appropriate diagnostics (eg, biliary brushings and biopsy) can be performed (10). In sphincter of Oddi dysfunction, therapy is manometically directed rather than fluoroscopically directed, although cholangiopancreatograms are also obtained to confirm the absence of structural abnormalities. As for colonoscopy, cost-effectiveness of the ERCP is conditional upon therapy being able to be performed at the time of the procedure. In cases of obstruction or duct leak, diagnostic ERCP that introduces contaminated dye into the obstructed or leaking region without therapeutic drainage is dangerous. Awaiting a subsequent radiologists' interpretation of the fluoroscopic images saved by the endoscopist, and then deciding on therapy via a repeat ERCP, is clearly inappropriate.

The present study has shown a significant discrepancy between the endoscopist's interpretation of the cholangiopancreatograms at the time of the procedure and the post-ERCP interpretation of fluoroscopic images by the radiologist. In
$53 \%$ of cases (20 of 38), in which definite pathology was seen by the endoscopist (stones, bile leaks), the radiology report did not report these findings. In keeping with our observations, a recent abstract (11), reporting results on 35 American patients undergoing routine post-ERCP interpretation by a radiologist, showed radiologist-endoscopist discordance rates in reading pancreatograms and cholangiograms of 55\% and $43 \%$, respectively, with no apparent added benefit in terms of patient care. That study had an 'effectiveness' approach (ie, the radiologists were not blinded), whereas the present study examined the 'efficacy' of a radiologist, without the 'real-life' assistance of either clinical information or the ERCP endoscopist's preliminary interpretation. Each approach has its own merit.

One possible explanation for this discrepancy is inadequate still image acquisition by the endoscopist to allow the radiologist to accurately make an interpretation. However, the rate of discrepancy was very similar for the two ERCP endoscopists. Also, the study was designed after the ERCPs were completed, limiting the endoscopist's subconscious biases that may have influenced which types of representative radiographs were taken. In cases of cholangitis, in which a stone is removed or a stent inserted, overfilling the biliary tree with dye to obtain representative images may increase the risk of bacteremia. Similarly, in the case of bile leaks, overinjection of dye to better demonstrate the leak on a static image may result in unnecessary spillage of contaminated dye into the 
gallbladder fossa or subhepatic space. Prolonging procedures unnecessarily to take extra pictures can potentially also increase radiation exposure to the patient, endoscopist, nurses and radiology technicians. In some institutions, wherein a radiologist may be nearby in the unit and accessible, it may be feasible to selectively consult the radiologist in real-time to help interpret an equivocal abnormality. With increasing frequency, ERCP rooms are being designed as part of endoscopy units, rather than part of radiology units, so this is not feasible in many places.

The applicability of the results of the present study to other centres has some limitations, although similar findings have been reported by others $(9,11)$. There is significant variability in the quality of fluoroscopy equipment. In centres with older equipment, the endoscopist may not feel comfortable making all of the final interpretations and decisions about therapeutic intervention. Similarly, differences in the amount and quality of ERCP training, as well as the numbers of cases performed may influence the endoscopist's expertise and comfort in interpreting the fluoroscopic images. Finally, biasing the radiologist with clinical and procedural data, as is commonly done in many centres as part of standard practice, undoubtedly improves the degree of agreement; however, this is arguably artificial and of limited clinical relevance. A radiologist without an accurate or consistent interpretation can artificially achieve high accuracy and consistency simply by repeating the endoscopist's wording in their submitted report. This system of having the ERCP endoscopist's interpretation available to the radiologist, however, prevents some of the anticipated medico-legal problems of charting discrepant results that would otherwise tend to accompany blinded independent interpretations.

One argument in favour of post-ERCP image interpretation by radiologists is the concern regarding the potential of the endoscopist to miss significant abnormalities. In $7 \%$ of cases in the present study, the radiologist reported a finding not included in the endoscopy report. However, the ERCP images were re-reviewed by the endoscopist in these cases, and a repeat ERCP was not believed to be clinically indicated in all except one of the seven patients. That patient had recurrent pancreatitis in the setting of pancreatic sphincter hypertension and underwent repeat manometry. None of these cases had subsequent clinical outcomes in the follow-up period to suggest that these were indeed true findings missed by the endoscopist. It is easier to differentiate stones from air bubbles on real-time fluoroscopy, and one is able to thoughtfully avoid overinterpreting 'pruning' on a cholangiogram in the setting of an intentionally underfilled biliary system (eg, in someone with cholangitis).

There are significant potential negative medico-legal implications of having discrepant ERCP reports on a patient's chart (12). Discrepant reports put the physician and patient in a difficult position. Should ERCP be repeated in these cases, or should the endoscopist re-review their films, assume that their interpretation at the time of the procedure was correct and follow the patient clinically? In low-suspicion cases, reviewing the images with the radiologist to gauge their degree of suspicion of an abnormality would be helpful. Given that the endoscopist has the advantage of real-time imaging and endoscopic visualization, following the patient clinically appears to be preferable to avoid exposing the patient to the risk of an unnecessary repeat ERCP in most cases.
It has been suggested that the best approach is selective consultation with the radiologist in cases in which a second opinion is sought (9). This would eliminate erroneous discrepant reports in routine cases. There would also be a decrease in the cost of an ERCP corresponding to the radiologist's interpretation fee. The magnitude of this cost is variable across provinces: only $\$ 22$ for the technical component and $\$ 9$ for the professional component in Ontario (Ontario provincial fee schedule 2007), but over $\$ 65$ per case in Alberta (Alberta provincial fee schedule 2003). There are some potential disadvantages to this selective approach. The question of when a second opinion should be sought remains unclear. Also, a decrease in the number and variety of films reviewed by radiologists may result in a lack of experience and the critical numbers necessary for them to maintain their skills. Therefore, reserving only the unusual and challenging cases for a second opinion by the radiologist is not without its own potential drawbacks. However, this is admittedly already occurring - radiologists interpreting ERCP films know that interpretation has already taken place and that therapy has already been applied. Some radiology-generated ERCP reports are already becoming abbreviated, at times simply documenting that the procedure took place, documenting the amount of fluoroscopy time involved, and which ducts were injected, and then referring to the endoscopist's report 'for details'. Radiologists typically may not follow ERCP literature and may not understand why a pancreatic duct stent is placed in what looks like an unobstructed pancreatic system, when the purpose of the stent is to prevent post-ERCP pancreatitis in a high-risk patient, and they may then look hard for another interpretation.

Overall, the best approach for the interpretation of the fluoroscopic images during ERCP remains unknown. It is likely that there is not a single approach that works best for all endoscopists and centres. The present study is not meant to be a comparison between endoscopists and radiologists at interpreting ERCP images, because only the radiologists were blinded to clinical history. However, the present study does show that the current system of routine post-ERCP interpretation of fluoroscopic images by radiologists may not contribute significantly to the care of the patient, and that the potentially discrepant reports on the same procedure may complicate matters for the patient and for the endoscopist.

This study was performed at the University of Calgary's Advanced Therapeutic Endoscopy Centre, Calgary, Alberta.

PREVIOUS PRESENTATION AND PUBLICATION: The abstract was presented at the American Gastroenterology Association's annual meeting at the Digestive Disease Week in New Orleans, May 15 to 19, 2004, and was published in Gastrointestinal Endoscopy 2004;59:AB186.

SPONSORS/DISCLOSURE: Dr Romagnuolo was funded by the Alberta Heritage Foundation for Medical Research as a population health investigator.

\section{REFERENCES}

1. Soto JA, Barish M, Yucel EK, Siegenberg D, Ferrucci JT, Chuttani R. Magnetic resonance cholangiography: Comparison with endoscopic retrograde cholangiopancreatography. Gastroenterology 1996;110:589-97.

2. Lee MG, Lee HJ, Kim MH, et al. Extrahepatic biliary diseases: 3D MR cholangiopancreatography compared with endoscopic retrograde cholangiopancreatography. Radiology 1997;202:663-9. 
3. Reinhold C, Taourel P, Bret PM, et al. Choledocholithiasis: Evaluation of MR cholangiography for diagnosis. Radiology 1998;209:435-42.

4. Prat F, Amouyal G, Amouyal P, et al. Prospective controlled study of endoscopic ultrasound and endoscopic retrograde cholangiography in patients with suspected common-bile duct lithiasis. Lancet 1996;347:75-9.

5. Canto MI, Chak A, Stellato T, Sivak MV Jr. Endoscopic ultrasonography versus cholangiography for the diagnosis of choledocholithiasis. Gastrointest Endosc 1998;47:439-48.

6. Loperfido S, Angelini G, Benedetti G, et al. Major early complications from diagnostic and therapeutic ERCP: A prospective multicenter study. Gastrointest Endosc 1998;48:1-10.

7. Freeman ML, DiSario JA, Nelson DB, et al. Risk factors for postERCP pancreatitis: A prospective, multicenter study. Gastrointest Endosc 2001;54:425-34.

8. Freeman ML, Nelson DB, Sherman S, et al. Same-day discharge after endoscopic biliary sphincterotomy: Observations from a prospective multicenter complication study. The Multicenter Endoscopic Sphincterotomy (MESH) Study Group. Gastrointest Endosc 1999;49:580-6.

9. Sweeney JT, Shah RJ, Martin SP, Ulrich CD Jr, Somogyi L. The impact of post-procedure interpretation of ERCP X-ray films by radiologists on patient care: Should it be routine or selective? Gastrointest Endosc 2003;58:549-53.

10. Hilsden RJ, Romagnulo J, May GR. Patterns of use of endoscopic retrograde cholangiopancreatography in a Canadian province. Can J Gastroenterol 2004;18:616-24.

11. Kucera S, Isenberg G, Chak A, Wong RC, Faulx AL, Sivak MV. Post-procedure radiologist's interpretation of endoscopic retrograde cholangiopancreatography (ERCP) X-ray films: A prospective outcomes study and cost analysis. Gastrointest Endosc 005;61:A1282. (Abst)

12. Thomas M, Geenen JE, Catalano M. Importance of real time interpretation (INTERP) of ERCP films over conventional static images: Medicolegal implications. Gastrointest Endosc 2004;59:183. (Abst) 


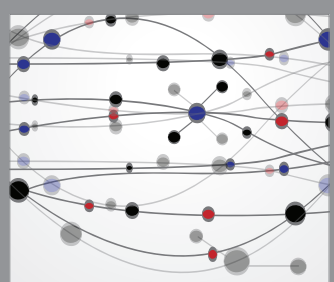

The Scientific World Journal
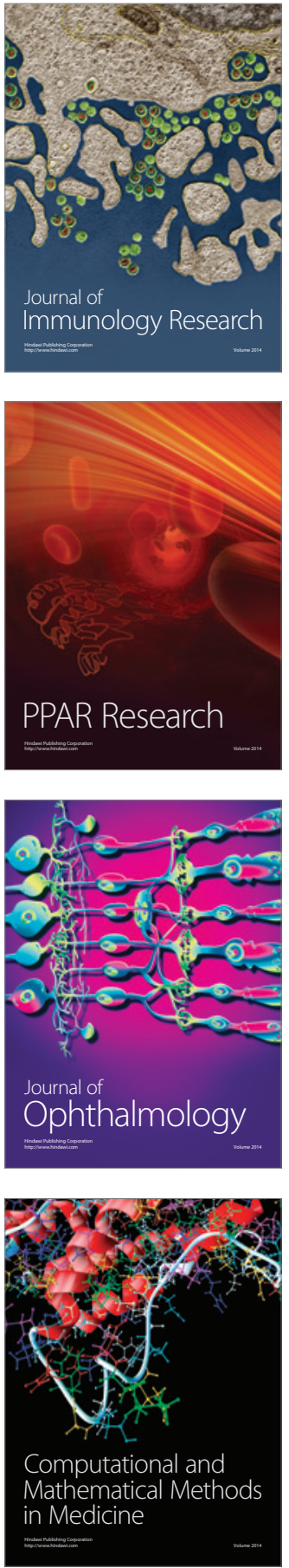

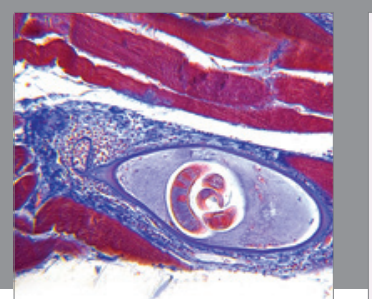

Gastroenterology Research and Practice

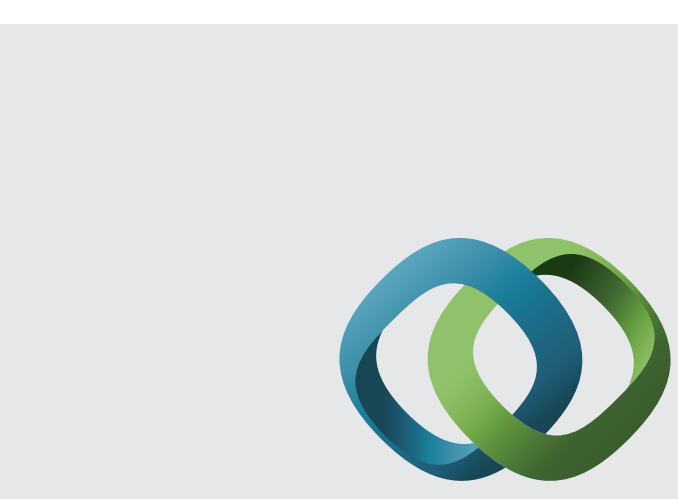

\section{Hindawi}

Submit your manuscripts at

http://www.hindawi.com
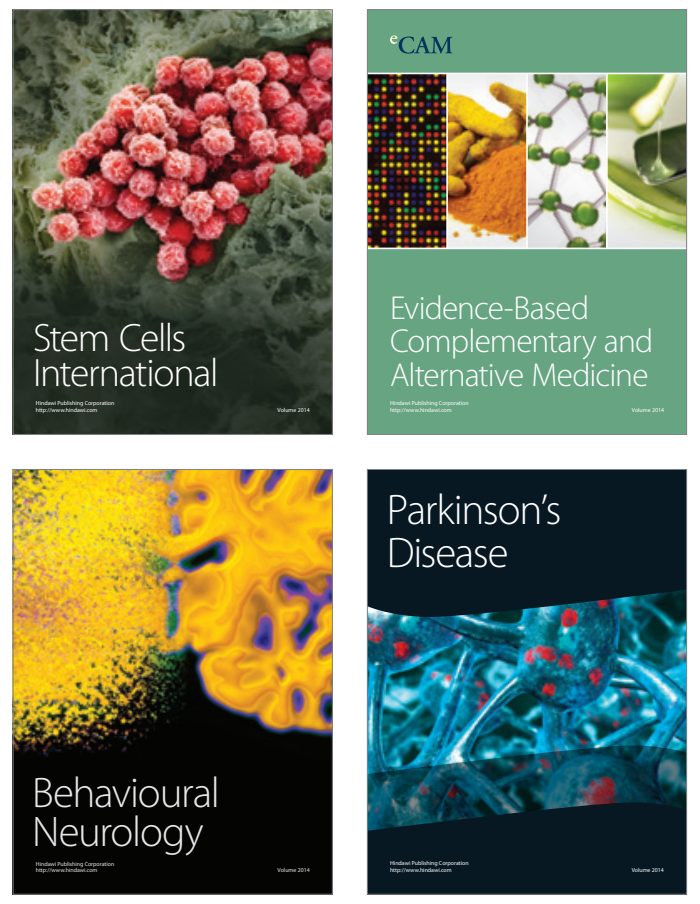
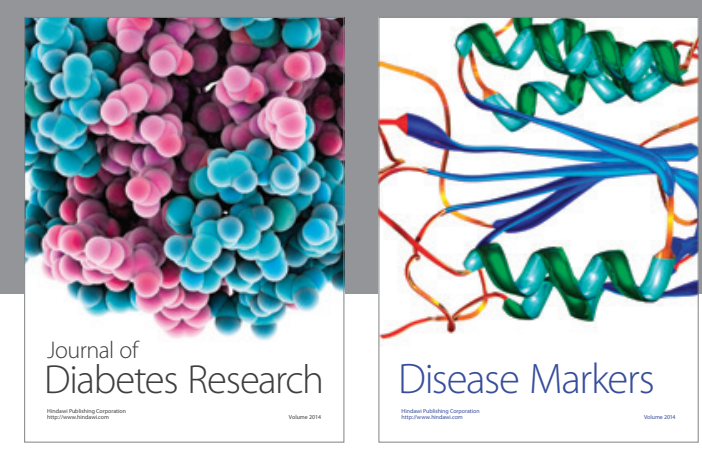

Disease Markers
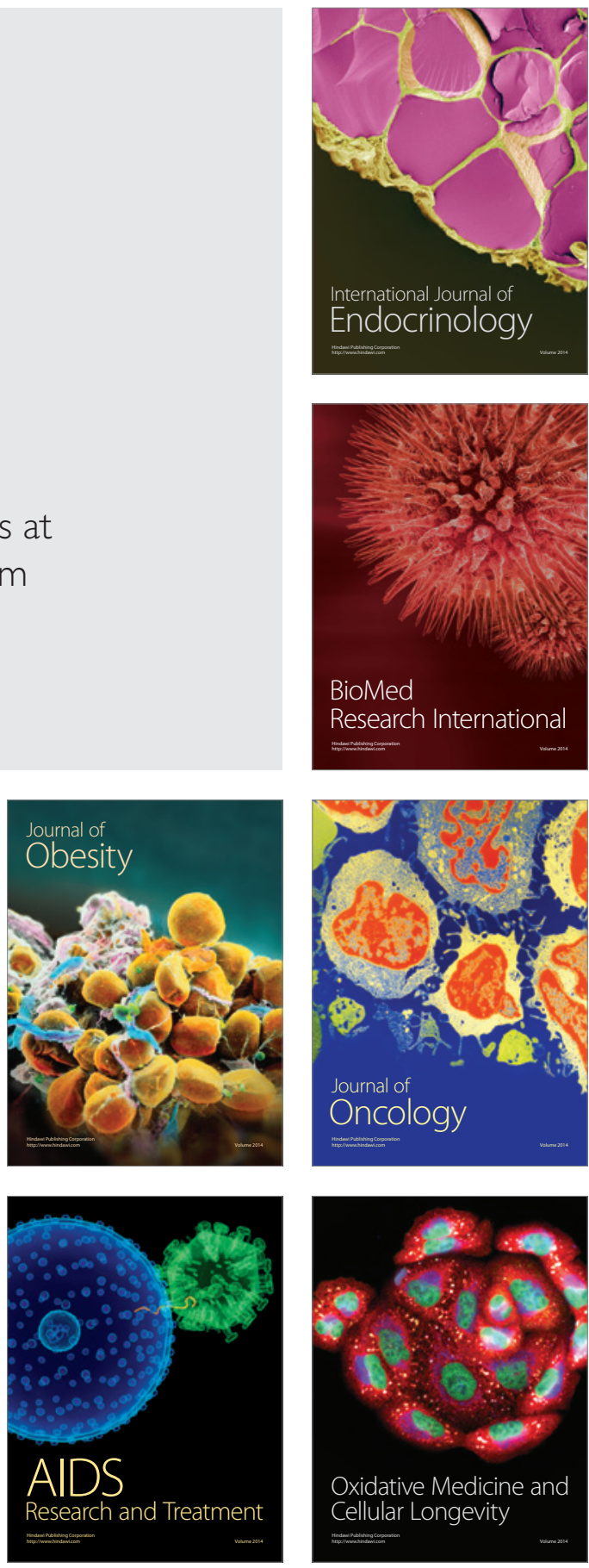